University of Nebraska - Lincoln

DigitalCommons@University of Nebraska - Lincoln

Electron Attachment to Dye-Sensitized Solar Cell Components:

Cyanoacetic Acid

Alberto Modelli

Paul Burrow

Follow this and additional works at: https://digitalcommons.unl.edu/physicsburrow

Part of the Atomic, Molecular and Optical Physics Commons

This Article is brought to you for free and open access by the Research Papers in Physics and Astronomy at DigitalCommons@University of Nebraska - Lincoln. It has been accepted for inclusion in Paul Burrow Publications by an authorized administrator of DigitalCommons@University of Nebraska - Lincoln. 


\title{
Electron Attachment to Dye-Sensitized Solar Cell Components: Cyanoacetic Acid
}

\author{
Alberto Modelli ${ }^{1}$ and Paul D. Burrow ${ }^{2}$ \\ 1 Dipartimento di Chimica “G. Ciamician”, Università di Bologna, via Selmi 2, \\ 40126 Bologna, Italy, and Centro Interdipartimentale di Ricerca in Scienze \\ Ambientali, Università di Bologna, via S. Alberto 163, 48123 Ravenna, Italy \\ 2 Department of Physics and Astronomy, University of Nebraska-Lincoln, \\ Lincoln, Nebraska 68588-o111, United States \\ Corresponding author - A. Modelli, email alberto.modelli@unibo.it

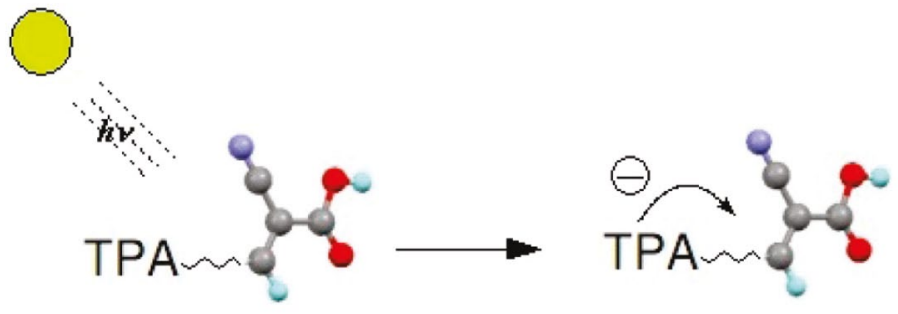

\begin{abstract}
The energies of electron attachment associated with temporary occupation of the lower-lying virtual orbitals of cyanoacetic acid (CAA), proposed as a possible component of dye-sensitized solar cells, and its derivative methyl cyanoacetate (MCA) are measured in the gas phase with electron transmission spectroscopy (ETS). The corresponding orbital energies of the neutral molecule, supplied by B3LYP/6-31G(d) calculations and scaled using an empirically calibrated linear equation, are compared with the experimental vertical attachment energies (VAEs). The vertical and adiabatic electron affinities are also evaluated at the B3LYP/6-31+G(d) level as the anion/neutral total energy difference. Dissociative electron attachment spectroscopy
\end{abstract}

Published in The Journal of Physical Chemistry A 115 (2011), pp 1100-1107.

doi:10.1021/jp110813f

Copyright (C) 2011 American Chemical Society. Used by permission.

Submitted November 12, 2010; revised December 23, 2010; published January 19, 2011. 
(DEAS) is used to measure the total anion current as a function of the incident electron energy in the $\mathrm{O}-4 \mathrm{eV}$ energy range, and the negative fragments generated through the dissociative decay channels of the molecular anion are detected with a mass filter. In both compounds only two intense fragment anion currents are observed, that due to loss of a hydrogen atom from the molecular anion ([M- $\left.\mathrm{H}]^{-}\right)$ and that due to formation of $\mathrm{CN}^{-}$. In CAA the former signal displays a very sharp feature at $0.68 \mathrm{eV}$, assigned to a vibrational Feshbach resonance arising from coupling between a dipole bound anion state and a temporary $\sigma^{\star}$ anion state.

\section{Introduction}

Solar energy is the most abundant source of energy on earth, and its conversion into electrical energy is, therefore, seen as one of the most promising solutions for the replacement of fossil fuels. Inorganic semiconductors are being increasingly employed in photovoltaic conversion, ${ }^{1}$ but organic alternatives, although their performance is still worse, are less expensive and may show advantages in their manufacturing and employment. ${ }^{2}$ Within this context, dye-sensitized solar cells have received considerable attention over the past decade. ${ }^{2-7}$ Generation of an electric current involves a complex sequence of processes. A key step of the mechanism is electron injection from a photoexcited state of the dye into the conduction band of a nanocrystalline $\mathrm{TiO}_{2}$ or $\mathrm{ZnO}$ film. In addition to good conversion efficiency, long-term stability of the whole system is an important requirement. Metal-free organic dyes generally consist of conjugated oligomers with reduced band gaps ${ }^{5}$ or large $\pi$-systems combining donor and acceptor blocks. ${ }^{-11}$ Recently, encouraging results were obtained using dyes comprising triphenylamine ${ }^{9,10}$ or phenothiazine ${ }^{11}$ moieties (as the electron donor) connected through one or two ethene bridges to rhodanine-3-acetic acid ${ }^{9,11}$ or cyanoacetic acid ${ }^{10,11}$ moieties (as the electron acceptor). Light absorption causes an intramolecular charge transfer from the donor to the acceptor block, anchored to the $\mathrm{TiO}_{2}$ film via its carboxyl group.

The gas-phase empty-level electronic structure of the acceptor molecule rhodanine-3-acetic acid has recently been studied ${ }^{12,13}$ using electron transmission spectroscopy (ETS), ${ }^{14}$ dissociative electron attachment spectroscopy (DEAS) ${ }^{15,16}$ and theoretical calculations. The ETS technique devised by Sanche and Schulz ${ }^{14}$ is still one of the most suitable means for observing the formation of temporary anions in the gas 
phase. Since electron attachment is rapid with respect to nuclear motion, temporary anions are formed in the equilibrium geometry of the neutral molecule. The measured vertical attachment energies (VAEs) are thus the negative of the vertical electron affinities $\left(\mathrm{EA}_{\mathrm{v}} \mathrm{s}\right)$. Additional information on the fate of the molecular anions observed in ETS can be supplied by DEAS which measures the yield of mass-selected negative ions as a function of electron impact energy. Under suitable energetic conditions, the decay of unstable molecular anions formed by resonant electron attachment can follow a dissociative channel which generates negative and neutral fragments, in kinetic competition with simple re-emission of the extra electron.

In connection with its use in dyes for solar cells, rhodanine-3- acetic acid was found ${ }^{12}$ to be a good electron acceptor due to the large EA of the $\pi(C=S)$ functional group. The DEA spectra, however, showed that the bonds of both the rhodanine pentacyclic ring and its carboxylic substituent are prone to cleavage upon addition of low-energy electrons. Although in the condensed phase, interactions with neighboring molecules stabilize the molecular anions, likely reducing their dissociative cross section, ${ }^{17}$ the occurrence of decomposition under conditions of excess negative charge would, of course, damage the dye and reduce the long-term stability of the whole device.

Park et al. ${ }^{11}$ compared the performances of dye-sensitized solar cells based on phenothiazine as the donor moiety, connected via an ethene double bond to rhodanine-3-acetic acid or cyanoacetic acid (CAA). They found that the organic dyes with CAA gave a notably higher efficiency. This finding was not attributed to poorer electron-acceptor properties of the rhodanine derivative, but to lack of conjugation (caused by the intermediate $\mathrm{CH}_{2}$ group) between its carboxylic group anchored to $\mathrm{TiO}_{2}$ and the dye $\pi$-system.

Here we apply the ETS and DEAS techniques to CAA (see Chart 1) to characterize its empty-level electronic structure and evaluate its possible tendency to dissociate upon electron addition.

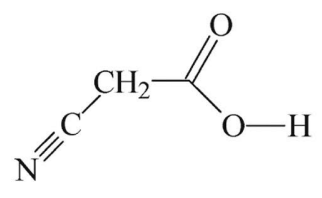

CAA

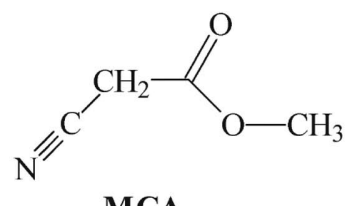

MCA

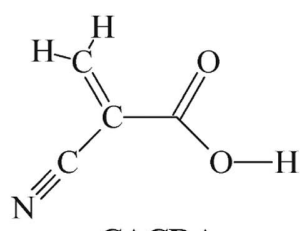

CACRA

Chart 1 
According to the literature, the most intense signal in the DEA spectra of small organic acids, ${ }^{18}$ amino acids, ${ }^{19}$ and alcohols ${ }^{20}$ at low energies is associated with the production of the fragment anion $[\mathrm{M}-\mathrm{H}]^{-}$ generated by loss of a hydrogen atom. To elucidate the role of the $\mathrm{OH}$ bond in CAA in this regard, we also compare our results with those obtained for its derivative methyl cyanoacetate (MCA, see Chart 1).

The density functional theory (DFT) method with the B3LYP hybrid functional ${ }^{21,22}$ is employed to reproduce the VAEs measured in the ET spectra, describe the localization properties of the corresponding anion states, and evaluate the thermodynamic energy thresholds for production of the fragment anions detected in the DEA spectra.

\section{Experimental methods}

Our electron transmission apparatus is in the format devised by Sanche and Schulz ${ }^{14}$ and has been previously described. ${ }^{23}$ The ETS technique takes advantage of the sharp variations in the total electron-molecule scattering cross section caused by resonance processes, namely, temporary capture of electrons with appropriate energy and angular momentum into empty MOs. ${ }^{15}$ To enhance the visibility of the sharp resonance structures, the impact energy of the electron beam is modulated with a small ac voltage, and the derivative of the electron current transmitted through the gas sample is measured directly by a synchronous lock-in amplifier. Each resonance is characterized by a minimum and a maximum in the derivative signal. The energy of the midpoint between these features is assigned as the VAE. The spectra of CAA and MCA were obtained using the apparatus in the "high-rejection" mode ${ }^{24}$ and are, therefore, related to the nearly total scattering cross sections. The electron beam resolution was about 50 $\mathrm{meV}$ (fwhm). The energy scale was calibrated with reference to the $\left(1 \mathrm{~s}^{1} 2 \mathrm{~s}^{2}\right)^{2} \mathrm{~S}$ anion state of He. The estimated accuracy is $\pm 0.05 \mathrm{eV}$. The cyanoacetic acid and methyl cyanoacetate samples were commercially available, and the collision chamber was heated to about 60 and 40 ${ }^{\circ} \mathrm{C}$, respectively, to obtain a suitable vapor pressure.

The collision chamber of our ETS apparatus has been modified ${ }^{25}$ to allow for ion extraction at $90^{\circ}$ with respect to the incident electron beam direction. Ions are then accelerated and focused toward 
the entrance of a quadrupole mass filter. Alternatively, the total anion current can be collected and measured with a picoammeter at the walls of the collision chamber (about $0.8 \mathrm{~cm}$ from the electron beam). Measurements of the total and mass-selected anion currents were obtained with an incident electron beam current about twice as large as that used for the ET experiment. The energy spread of the electron beam increased to about $110 \mathrm{meV}$, as evaluated from the width of the $\mathrm{SF}_{6}{ }^{-}$signal at zero energy used for calibration of the energy scales.

Calculations were performed with the Gaussian 03 set of programs. ${ }^{26}$ Evaluation of the virtual orbital energies (VOEs) of the neutral molecule was performed at the B3LYP/6-31G(d) level. ${ }^{21}$ The vertical electron affinity $\left(\mathrm{EA}_{v}\right)$ was calculated as the difference between the total energy (only electronic contributions) of the neutral and the lowest anion state, both in the optimized geometry of the neutral state, using the B3LYP hybrid functional with the standard $6-31+G(d)$ basis set. The adiabatic electron affinity $\left(\mathrm{EA}_{\mathrm{a}}\right.$ ) was obtained as the energy difference between the neutral and the lowest anion state, each in its optimized geometry.

\section{Results and discussion}

\section{Empty Level Structure: ET Spectra of CAA and MCA, Calculated VAEs and EAs}

CAA and MCA possess an empty $\pi^{*}$ molecular orbital (MO) with primarily carbonyl character and two perpendicular (degenerate in energy in $\mathrm{HCN}$ ) $\pi^{*}$ MOs mainly localized on the $\mathrm{C}-\mathrm{N}$ triple bond. Because of the intervening $\mathrm{CH}_{2}$ group, the two $\pi$-systems are not conjugated, so their mutual perturbations are expected to occur mainly through inductive effects and, to some extent, hyperconjugation mediated by the $\mathrm{CH}_{2}$ group itself. The $\pi{ }^{*} \mathrm{CO}$ MO (VAE $=1.31$ $\mathrm{eV}$ in $\left(\mathrm{CH}_{3}\right)_{2} \mathrm{CO}^{27}$ and $1.73 \mathrm{eV}$ in $\left.\mathrm{HCOOH}^{28}\right)$ is destabilized by mixing with the oxygen lone pair of the hydroxyl group, whereas the electron-withdrawing inductive effect of the cyano group acts in the opposite direction. The VAE of the $\pi^{*}{ }_{\mathrm{CN}} \mathrm{MOs}$ is $2.3 \mathrm{eV}$ in $\mathrm{HCN}^{29}$ and $2.82 \mathrm{eV}$ in $\mathrm{CH}_{3} \mathrm{CN} .{ }^{30}$

The ET spectra of CAA and MCA in the $0-6 \mathrm{eV}$ energy range are reported in Figure 1. Two distinct resonances are displayed, centered 


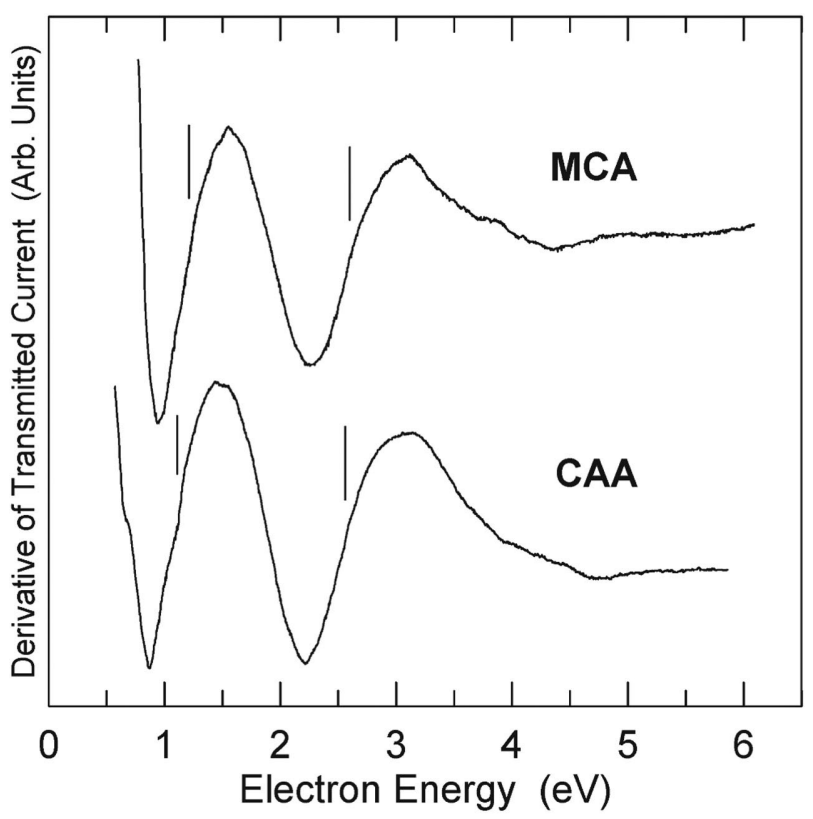

Figure 1. Derivative of transmitted current, as a function of electron energy, in gasphase cyanoacetic acid (CAA) and methyl cyanoacetate (MCA). Vertical lines locate the VAEs.

at 1.11 and $2.56 \mathrm{eV}$ in the former and 1.21 and $2.60 \mathrm{eV}$ in the latter, in line with the above qualitative predictions.

For a more accurate interpretation of the spectral features, theoretical calculations were carried out. An adequate approach for describing unstable anion states involves difficulties not encountered for neutral or cation states. ${ }^{31-34}$ The most correct method is, in principle, the calculation of the total scattering cross section with the use of continuum functions, but complications arise from the lack of an accurate description of the electron-molecule interaction. ${ }^{35}$ However, it has been demonstrated 31,33 that good linear correlations can be obtained between the $\pi^{*}{ }_{C C}$ VAEs measured in unsaturated hydrocarbons and the corresponding virtual orbital energies (VOEs) of the neutral molecules obtained with simple Hartree-Fock (HF) calculations, using basis sets that do not include diffuse functions. More recently, it has been shown ${ }^{36}$ that the neutral-state $\pi^{*}$ VOEs obtained with DFT B3LYP/6$31 \mathrm{G}(\mathrm{d})$ calculations also supply a good linear correlation with the corresponding VAEs measured over a variety of different families of unsaturated compounds. A more accurate correlation is expected if the scaling equation is calibrated with "training" compounds structurally 

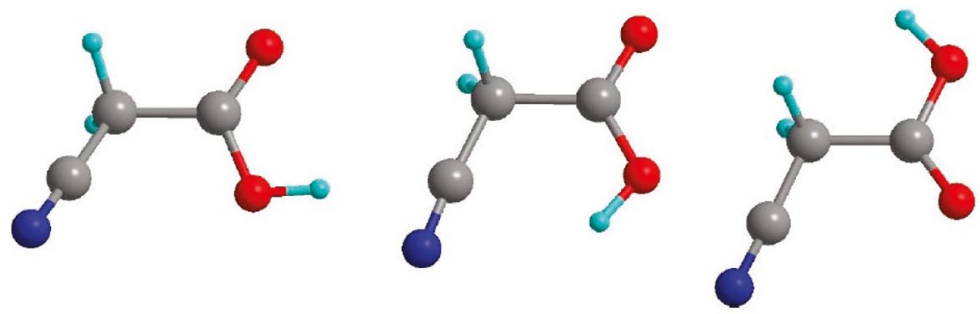

Figure 2. Geometrical structures of the three most stable conformers of cyanoacetic acid (CAA), as supplied by B3LYP/6-31+G(d) calculations.

close to the subject molecule. For this reason, here we use an empirical linear correlation $\left(\mathrm{VAE}(\mathrm{eV})=1.112 \mathrm{VOE} \pm 1.631 ; r^{2}=0.963\right)$ obtained from the experimental $\pi^{*}$ VAEs of selected small $\pi$ - systems containing carbonyl or cyano groups (cyclobutanone, 2-oxacyclobutanone, 3-oxacyclobutanone, tetramethyl-1,3-cyclobutandione, cyclopentanone, acetone, $\left.\mathrm{HCN}, \mathrm{CH}_{3} \mathrm{CN}\right)$ and the corresponding VOEs supplied by B3LYP/6-31G(d) calculations.

For the ground neutral state of CAA three local minima, corresponding to different conformers (see Figure 2), are calculated. According to the total energies (only electronic contributions) supplied by B3LYP/6$31 \mathrm{G}(\mathrm{d})$ calculations, conformer $\mathbf{1}$ is the most stable, conformers $\mathbf{2}$ and 3 lying, respectively, $0.155 \mathrm{eV}(3.6 \mathrm{kcal} / \mathrm{mol})$ and $0.314 \mathrm{eV}(7.2 \mathrm{kcal} /$ $\mathrm{mol}$ ) higher in energy (0.160 and $0.318 \mathrm{eV}$ with the $6-31+\mathrm{G}(\mathrm{d})$ basis set). Accounting for zero-point vibrational energy corrections, the energies of conformers $\mathbf{2}$ and $\mathbf{3}$ relative to that of conformer $\mathbf{1}$ (0.148 and $0.300 \mathrm{eV}$, respectively) are slightly reduced. The calculations predict the dipole moment of conformer $3(6.18 \mathrm{D})$ to be much larger than those of conformers $1(2.48 \mathrm{D})$ and $\mathbf{2}(1.96 \mathrm{D})$. However, the relative energies given above lead to a very small population (0.003\%) of conformer 3 at $60^{\circ} \mathrm{C}$.

The B3LYP/6-31G(d) energies of the first four empty MOs of CAA (conformer $\mathbf{1}$ ) and MCA are given in Table 1, together with the scaled $\pi^{*}$ VOEs and the VAEs measured in the ET spectra. Similar energy sequence and localization properties are supplied by HF calculations with the same basis set. Figure 3 shows the HF/6-31G(d)//MP2/6$31 \mathrm{G}(\mathrm{d})$ representation of the localization properties of these MOs in CAA. The B3LYP/6-31G(d) MOs are predicted to be somewhat more localized on both the carboxyl and cyano moieties. The scaled B3LYP 
Table 1. B3LYP/6-31G(d) VOEs (eV), Scaled VOEs (See Text), and Measured VAEs of CAA and MCA

\begin{tabular}{lcccr}
\multicolumn{3}{c}{ B3LYP/6-31G(d) } & & $\begin{array}{r}\text { expt } \\
\text { VAE }\end{array}$ \\
\cline { 1 - 3 } orbital & VOE & scaled VOE & \\
\hline & & CAA & & \\
$\sigma^{*}{ }_{\mathrm{OH}}$ & 1.392 & & & 2.56 \\
$\pi^{*} \mathrm{CN}$ & 0.748 & & 2.46 & 1.11 \\
$\pi^{*}{ }_{\mathrm{CN}}(\sigma)$ & 0.543 & & 2.24 & \\
$\pi^{*}{ }_{\mathrm{CO}}$ & -0.523 & & 1.05 & \\
& & MCA & & 2.60 \\
$\sigma^{*}{ }_{\mathrm{CH} / \mathrm{CO}}$ & 2.162 & & & 1.21 \\
$\pi^{*} \mathrm{CN}$ & 0.866 & & 2.59 & \\
$\pi^{*}{ }_{\mathrm{CN}}(\sigma)$ & 0.664 & & 2.37 & 1.25 \\
$\pi^{*}{ }_{\mathrm{CO}}$ & -0.346 & & & \\
\hline
\end{tabular}
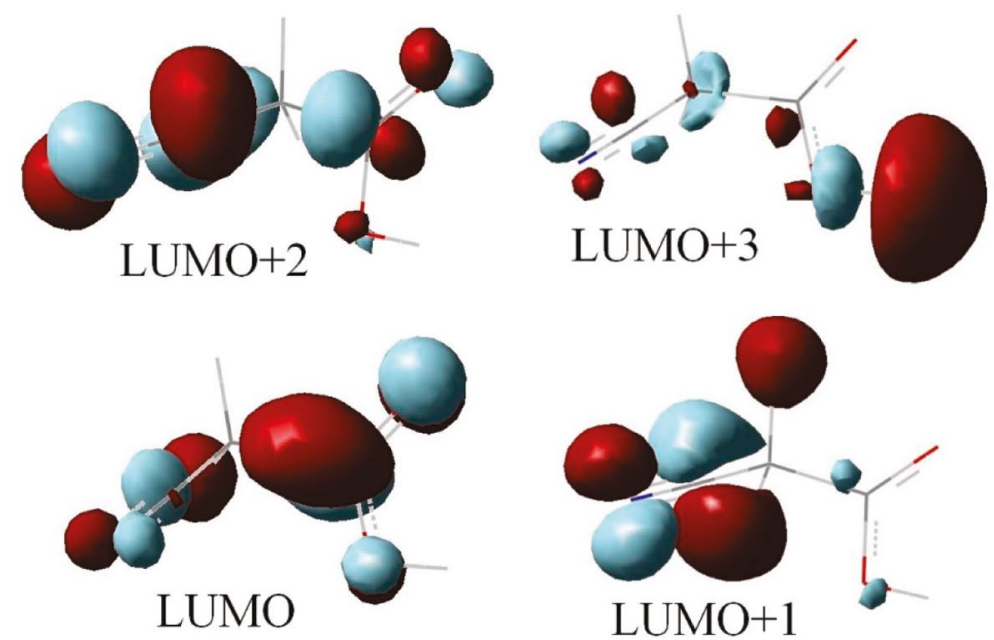

Figure 3. Representation of the four lowest-lying empty MOs of cyanoacetic acid (CAA), as supplied by HF/6-31G(d) calculations for the geometry optimized with the MP2/6-31G(d) method.

VOEs of the $\pi^{*}{ }_{\mathrm{CO}}$ and $\pi^{*}{ }_{\mathrm{CN}}$ MOs nicely match the measured VAEs (see Table 1). According to the calculations, the two perpendicular MOs with mainly $\pi_{\mathrm{CN}}^{*}$ character are split by only $0.2 \mathrm{eV}$, the lower one lying in the plane of the $\sigma$ framework. Consistently, the two contributions are not resolved in the ET spectrum because of their natural breadths. 
In contrast to resonances associated with occupation of $\pi^{*}$ MOs, low-lying $\sigma^{\star}$ resonances in molecules containing second row elements are hardly visible in ETS, primarily because of their short lifetimes but also because they may be obscured by intense $\pi^{*}$ resonances. Due to the absence of experimental VAEs with which to form a correlation, scaling is often problematic for $\sigma^{\star}$ resonances, as in the case of the $\sigma^{*}{ }_{\mathrm{OH}} \mathrm{MO}$ (LUMO +3 in Figure 3). Using the HF/6-31G(d) VOE $(5.696$ $\mathrm{eV})$ and the same scaling found ${ }^{37}$ for $\sigma^{\star}(\mathrm{C}-\mathrm{Cl})$ MOs in chloroalkanes, the $\sigma^{\star}{ }_{\mathrm{OH}}$ resonance would lie at $2.58 \mathrm{eV}$, i.e., at about the same energy of the $\pi^{*}{ }_{\mathrm{CN}}$ resonance, although this estimate is very rough. It can also be noted that the minimum addition of diffuse functions to the basis set stabilizes the $\sigma^{\star}{ }_{\mathrm{OH}}$ MO more than the $\pi^{\star}$ MOs. B3LYP/6$31+\mathrm{G}(\mathrm{d})$ calculations, in fact, locate the energy of the $\sigma^{*}{ }_{\mathrm{OH}} \mathrm{MO}$ (with rather large contributions from diffuse functions) about midway between the energies of the $\pi^{*}{ }_{\mathrm{CO}}$ and $\pi^{*}{ }_{\mathrm{CN}}$ MOs.

EAs can be obtained as the difference between the total energies of the ground anion state and the neutral state, both at the optimized geometry of the neutral species $\left(\mathrm{EA}_{\mathrm{v}}\right)$ or each with its optimized geometry $\left(\mathrm{EA}_{\mathrm{a}}\right)$. A proper description of the spatially diffuse electron distributions of anions normally requires a basis set with diffuse functions. ${ }^{88,39}$ However, calculated anion state energies decrease as the basis set is expanded so that the choice of a basis set that gives a satisfactory description of the energy and nature of the anion is a priori not obvious. ${ }^{40}$ Moreover, when basis sets that include diffuse functions are used, one has to ascertain that the singly occupied MO (SOMO) of the anion is not described as a diffuse function having no physical significance with respect to anion formation ${ }^{31,32,36,40}$ The more unstable the anion state, the larger is the need to augment the basis set with diffuse functions, but the larger is the probability that the extra electron is accommodated in an unphysically diffuse function. On the other hand, basis sets without diffuse functions largely overestimate the anion energies.

We illustrate this with a brief digression. Table 2 reports the energies (only electronic contributions) of the lowest vertical and adiabatic anion states of CAA and MCA relative to their neutral ground states, obtained using a basis set (6-31G(d)) without diffuse functions and a basis set $(6-31+G(d))$ with the smallest addition of diffuse functions ( $s$ - and $p$-type diffuse functions at the nonhydrogen atoms). 
Table 2. B3LYP Total Electronic Energies (eV) of the Anion States of CAA, MCA, and CACRA Relative to Their Ground Neutral States

\begin{tabular}{lcc} 
& $6-31 \mathrm{G}(\mathrm{d})$ & $6-31+\mathrm{G}(\mathrm{d})$ \\
\hline CAA & & \\
vertical anion & 2.043 & $0.642^{\mathrm{a}}$ \\
adiabatic anion & 1.122 & 0.233 \\
MCA & & \\
vertical anion & 2.052 & $0.867^{\mathrm{a}}$ \\
adiabatic anion & 1.132 & 0.351 \\
CACRA & & \\
vertical anion & -0.179 & -0.835 \\
adiabatic anion & -0.543 & -1.169 \\
\hline
\end{tabular}

a. The SOMO is described as a diffuse $\sigma^{\star}$ function.

As expected, the minimal basis set greatly overestimates (by about 1 $\mathrm{eV}$ ) the energy of the lowest vertical anion state of both compounds, whereas the energies obtained with the $6-31+G(d)$ basis set are about $0.4 \mathrm{eV}$ lower than the corresponding experimental VAEs. However, inspection of the MO localization properties reveals that although the expanded basis set correctly describes the LUMO of the neutral states and the SOMO of the adiabatic anion states as valence $\pi{ }_{\mathrm{CO}} \mathrm{MOs}$, the SOMOs of the vertical anions of both compounds are diffuse $\sigma^{*}$ functions. We can recover an approximation to the location of the $\pi^{*} \mathrm{VAE}$ by calculating the excitation energies of the vertical anions of CAA and MCA with the TD-DFT method. ${ }^{41}$ In both compounds, the first excited state of the vertical anion accommodates the extra electron in an MO of mainly $\pi_{\text {CO }}^{*}$ character. The B3LYP/6-31+G(d) excitation energies are found to be $0.436 \mathrm{eV}$ (CAA) and $0.302 \mathrm{eV}$ (MCA), and, when added to the vertical anion energies reported in Table 2, lead to values of the first VAE of $1.08 \mathrm{eV}$ for CAA and $1.17 \mathrm{eV}$ for MCA, in good agreement with experiment and with the corresponding scaled VOEs. Thus, in this case the $6-31+G(d)$ basis set is an adequate choice, while tests with an additionally expanded basis set indicate that the VAEs predicted with the same approach continue to decline in energy. This example illustrates some of the above-mentioned problems that arise with the use of diffuse basis sets for the description of unstable anion state. 


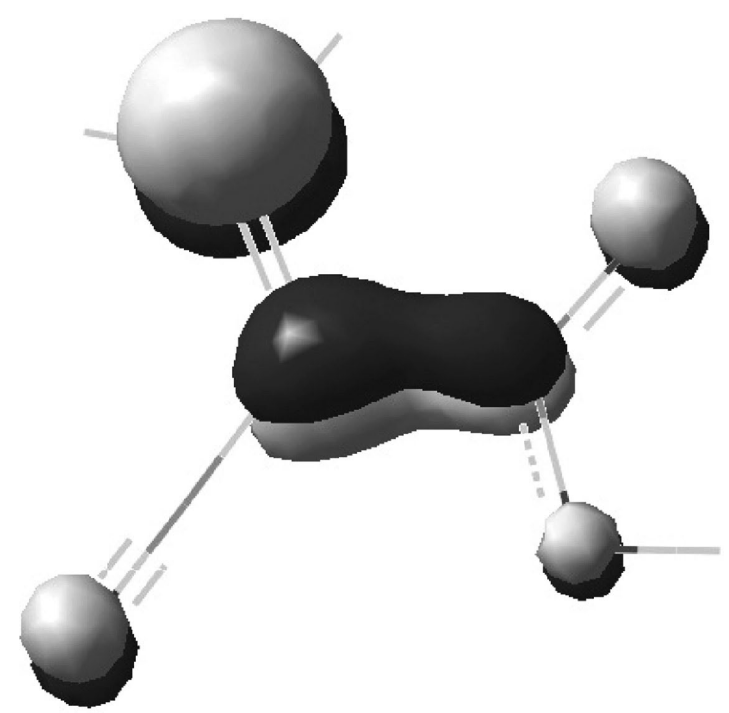

Figure 4. Representation of the LUMO of cyanoacrylic acid (CACRA), as supplied by B3LYP/6-31G(d) calculations.

Finally, it can be noted that because of the lack of conjugation between the cyano and carbonyl $\pi$-systems, the $\mathrm{EA}_{\mathrm{v}}$ of CAA is sizably negative, implying that this compound would not be a good choice as an electron acceptor. In fact, in the dye used for solar cells, CAA is connected to the donor block by replacement of its $\mathrm{CH}_{2}$ group with an ethene group. The electron-acceptor molecule can thus be considered to be cyanoacrylic acid (CACRA, see Chart 1), where the cyano, ethene, and carbonyl $\pi$-systems are conjugated between them and, in the dye, with the donor block via the ethene bridge. The $\mathrm{EA}_{\mathrm{v}}$ calculated for CACRA is appreciably positive ( $0.835 \mathrm{eV}$, see Table 2), and the LUMO is localized over the entire molecule (see Figure 4), thus favoring electron transfer from the donor block to the $\mathrm{TiO}_{2}$ film.

\section{Dissociative Electron Attachment to CAA and MCA}

Figure 5 reports the total anion current (top curve) measured in gas-phase CAA at the walls of the collision chamber $(0.8 \mathrm{~cm}$ from the electron beam) and the two most intense mass-selected fragment anion currents, as a function of the incident electron energy, in the 0-4 $\mathrm{eV}$ energy range. The peak energies are given in Table 3, together with the relative intensities of the fragment anion currents, as evaluated from the peak heights. The total anion current displays two broad, 


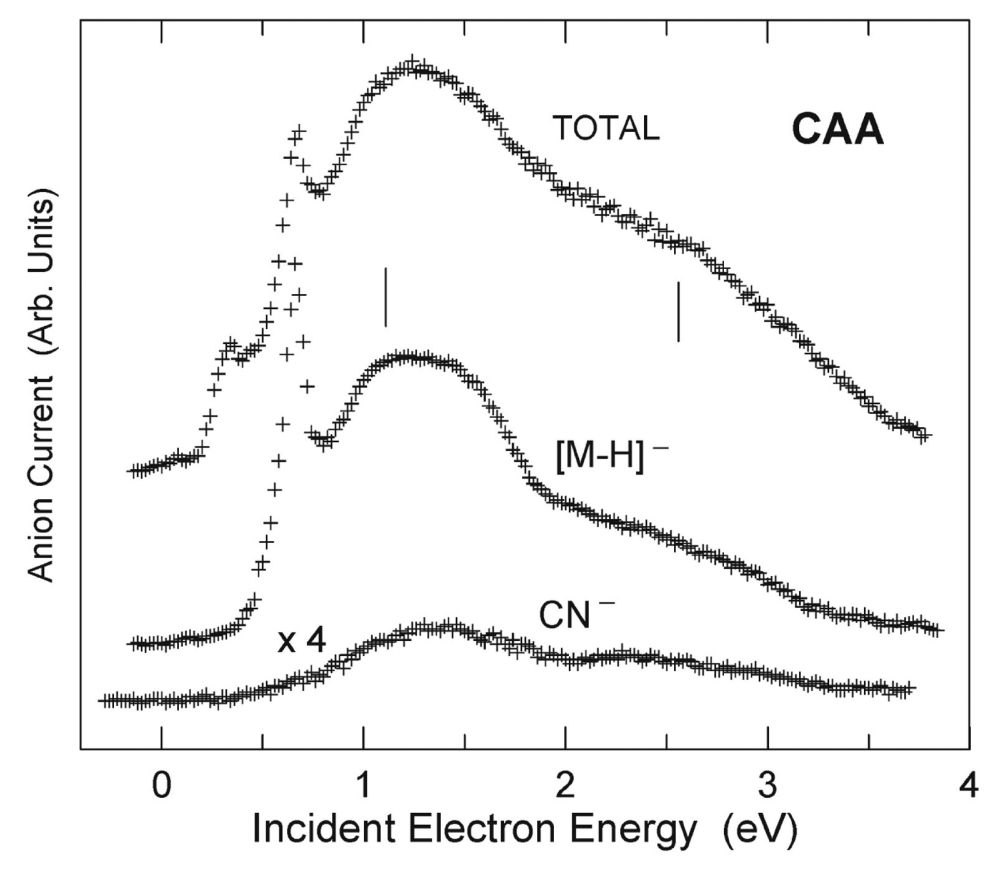

Figure 5. Total anion current and mass-selected anion currents, as a function of the incident electron energy, measured in gas-phase cyanoacetic acid (CAA).

Table 3. Peak Energies (eV) of the Total and Mass-Selected Negative Currents and Relative Intensities (from Peak Heights) Measured in the DEA Spectra of Cyanoacetic Acid (CAA)

\begin{tabular}{|c|c|c|c|}
\hline \multirow{2}{*}{$\begin{array}{l}\text { Total } \\
\text { peak energy }\end{array}$} & \multicolumn{3}{|c|}{ Mass-selected } \\
\hline & peak energy & fragment & rel int \\
\hline \multicolumn{4}{|c|}{ CAA } \\
\hline 0.34 & 0.68 & {$[\mathrm{M}-\mathrm{H}]^{-}$} & 100 \\
\hline 0.68 & 1.1 & {$[\mathrm{M}-\mathrm{H}]^{-}$} & 76 \\
\hline 1.2 & 2.3 & {$[\mathrm{M}-\mathrm{H}]^{-}$} & 26 \\
\hline \multirow[t]{2}{*}{2.4} & 1.3 & $\mathrm{CN}^{-}$ & 6 \\
\hline & 2.4 & $\mathrm{CN}^{-}$ & 3 \\
\hline \multicolumn{4}{|c|}{ MCA } \\
\hline 1.2 & 1.2 & {$[\mathrm{M}-\mathrm{H}]^{-}$} & 100 \\
\hline \multirow[t]{3}{*}{2.3} & 2.3 & {$[\mathrm{M}-\mathrm{H}]^{-}$} & 50 \\
\hline & 1.2 & $\mathrm{CN}^{-}$ & 15 \\
\hline & 2.3 & $\mathrm{CN}^{-}$ & 6 \\
\hline
\end{tabular}


overlapping signals peaking at 1.2 and $\sim 2.4 \mathrm{eV}$, energies very close to the $\pi^{*}$ VAEs measured in the ET spectrum. The vertical lines in Figure 5 locate the $\pi^{*}$ VAEs measured in ETS. The most striking features displayed by the total anion current are two sharp structures peaking at 0.34 and $0.68 \pm 0.05 \mathrm{eV}$, whose widths are limited by the electron beam resolution. The latter peak also appears prominently in the production of $[\mathrm{M}-\mathrm{H}]^{-}$.

An estimate for the absolute cross section for production of the total anion current can be obtained from comparison of absolute cross sections reported in the literature with our measurements on the same compounds (see ref 42 for more details). Although application of this procedure to CAA and rhodanine-3-acetic acid ${ }^{12}$ is problematic because of their relatively low volatility and the fact that, in the apparatus employed, the sample vapor pressure is measured outside the collision chamber, as a rough evaluation the maximum absolute DEA

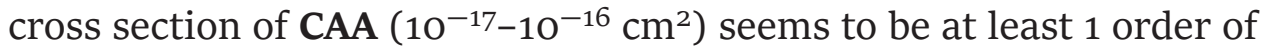
magnitude smaller than that of rhodanine-3-acetic acid.

The broad features with maxima at 1.2 and $\sim 2.4 \mathrm{eV}$ in the total anion current are accounted for by the two most intense mass-selected fragment anion currents, detected at $m / e=84$ and $m / e=26$ and assigned, respectively, to loss of a hydrogen atom from the molecular anion $\left([\mathrm{M}-\mathrm{H}]^{-}\right)$and to $\mathrm{CN}^{-}$. Each of the two negative fragments is produced at energies corresponding to the locations of both the $\pi^{*}{ }_{\mathrm{CO}}$ and the $\pi^{*}{ }_{\mathrm{CN}}$ resonances observed in ETS, the $\mathrm{CN}^{-}$current being about 12 times less intense than the $[\mathrm{M}-\mathrm{H}]^{-}$current. No signals at $m / e=85$ (corresponding to the parent molecular anion) were detected.

The calculated thermodynamic energy thresholds for the loss of a hydrogen atom from the molecular anion and for production of the $\mathrm{CN}^{-}$fragment are given in Table 4. To verify that the 6-31+G(d) basis set is not too small, we calculated the energy threshold for $\mathrm{CN}^{-}$ production from CAA including more diffuse functions $(6-31++\mathrm{G}(\mathrm{d}, \mathrm{p})$ basis set). The value obtained $(0.839 \mathrm{eV})$ is quite close to that (o.844 eV) supplied by the $6-31+\mathrm{G}(\mathrm{d})$ basis set.

The B3LYP/6-31+G(d) thresholds are about $0.8 \mathrm{eV}$ for production of the cyanide anion, and 0.7 and $1.1 \mathrm{eV}$, respectively, for the loss of a hydrogen atom from the $\mathrm{O}-\mathrm{H}$ and $\mathrm{CH}_{2}$ groups. A calculation at the same level for $\mathrm{H}$ loss from the $\mathrm{OH}$ group of $\mathrm{HCOOH}$ yields $1.328 \mathrm{eV}$, compared to the experimental onset observed by Pelc et al. ${ }^{18}$ of 1.15 
Table 4. B3LYP Energies (Only Electronic Contributions, eV) Relative to the Ground Neutral States of CAA and MCA

$6-31 G(d) \quad 6-31+G(d)$

\begin{tabular}{lccc}
\hline & CAA & & \\
$\mathrm{NCCH}_{2} \mathrm{C}(\mathrm{O}) \mathrm{O}^{-}+\mathrm{H}^{*}$ & & 1.321 & 0.702 \\
$\mathrm{NCCHC}(\mathrm{O}) \mathrm{OH}^{-}+\mathrm{H}^{*}$ & & 1.682 & 1.089 \\
${ }^{*} \mathrm{H}_{2} \mathrm{CC}(\mathrm{O}) \mathrm{OH}+\mathrm{CN}^{-}$ & & 1.905 & 0.844 \\
& $\mathrm{MCA}$ & & \\
& & 4.308 & 3.563 \\
$\mathrm{NCCH}_{2} \mathrm{C}(\mathrm{O}) \mathrm{OCH}_{2}{ }^{-}+\mathrm{H}^{*}$ & & 1.776 & 1.257 \\
$\left.\mathrm{NCCHC}^{*} \mathrm{O}\right) \mathrm{OCH}_{3}{ }^{-}+\mathrm{H}^{*}$ & 1.934 & 0.884 \\
${ }^{*} \mathrm{H}_{2} \mathrm{CC}(\mathrm{O}) \mathrm{OCH}_{3}+\mathrm{CN}^{-}$ & & & \\
\hline
\end{tabular}

$\pm 0.1 \mathrm{eV}$. Incorporating this difference, we thus expect the $[\mathrm{M}-\mathrm{H}]^{-}$ threshold in CAA to lie at 0.5 ( $0.1 \mathrm{eV}$. This value falls just below the sharp peak in $[\mathrm{M}-\mathrm{H}]^{-}$current in Figure 5 .

Because of the close proximity of the broad DEA peaks to the $\pi^{*}$ resonances determined by ETS, the major contribution to cleavage of these bonds of (local) $\sigma$ symmetry likely stems from initial electron occupation of the empty $\pi^{\star}$ MOs. In the case of $\mathrm{CN}^{-}$, this must arise through an out-of-plane distortion of this group. 43

To distinguish between the mechanisms for $\mathrm{H}$ atoms leaving from the $\mathrm{OH}$ and $\mathrm{CH}_{2}$ groups in CAA, we show in Figure 6 the DEA spectra of the methyl derivative (MCA) of cyanoacetic acid in which $\mathrm{OH}$ has been replaced by $\mathrm{OCH}_{3}$. The total and mass-selected anion currents are qualitatively similar to those recorded in CAA, except for the absence of the two low lying sharp structures. From a quantitative point of view, the intensity ratio between the $[\mathrm{M}-\mathrm{H}]^{-}$and $\mathrm{CN}^{-}$ currents (about 12 in CAA) is reduced to about 6 (see Table 3) due to replacement of the hydroxyl group by a methoxy group. Because the energy threshold calculated for the loss of a methyl $\mathrm{H}$ atom is approximately $3.6 \mathrm{eV}$ (Table 4), it is clear that the MCA molecular anion can lose a $\mathrm{H}$ atom only from the $\mathrm{CH}_{2}$ group over the energy range shown. It is informative to make a closer comparison of the production of $[\mathrm{M}-\mathrm{H}]^{-}$in CAA and MCA, and to this end we show in Figure 7 the two curves plotted together. To emphasize the similarity in the 


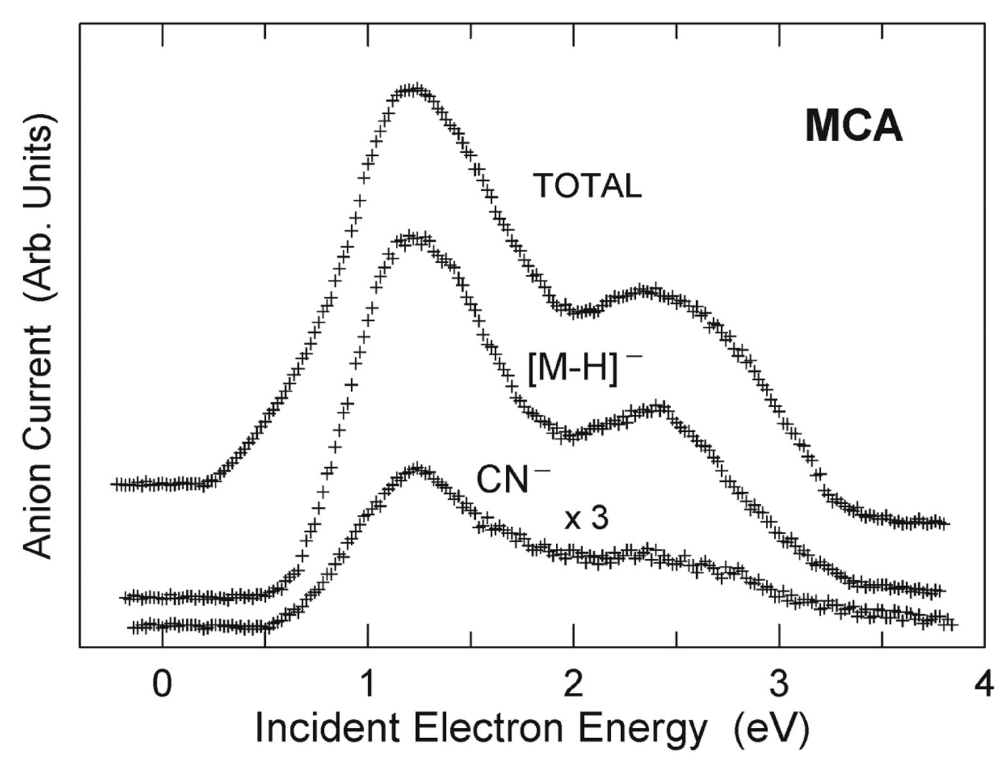

Figure 6. Total anion current and mass-selected anion currents, as a function of the incident electron energy, measured in gas-phase methyl cyanoacetate (MCA).

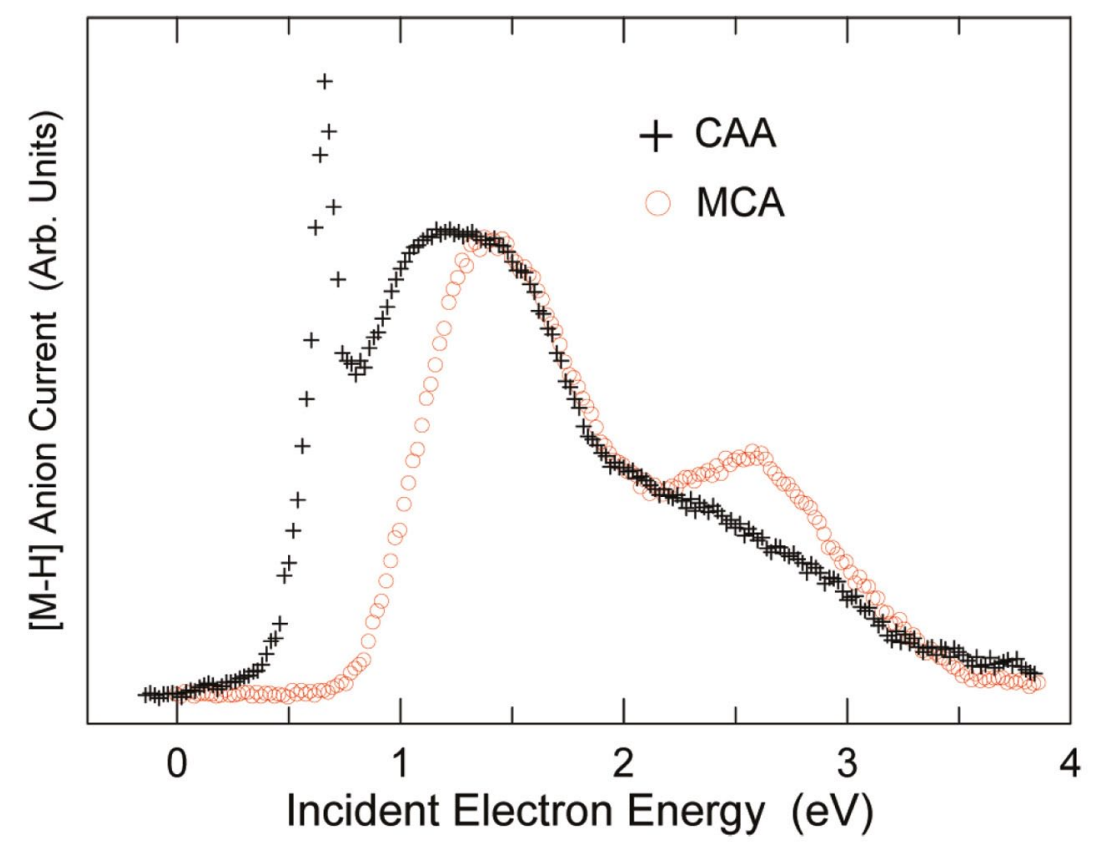

Figure 7. Comparison between the $[\mathrm{M}-\mathrm{H}]^{-}$fragment currents in CAA and MCA, with intensities normalized at $1.2 \mathrm{eV}$. 
structure arising from the $\mathrm{C}=\mathrm{O} \pi^{*}$ resonance, we have shifted the MCA curve higher by $0.1 \mathrm{eV}$ and normalized it to that of CAA. Over the range 1.4-2.2 eV, the curves are essentially identical. This figure clearly shows that a different mechanism prevails for the sharp peak and a portion of the low energy side of the broad $1.1 \mathrm{eV}$ feature which must arise from the $\mathrm{OH}$ group, and the remainder of the broad peak produced by $\mathrm{H}$ departure from the $\mathrm{CH}_{2}$ group. The latter process can clearly occur through the $\mathrm{C}=\mathrm{O} \pi^{*}$ resonance as the $\mathrm{H}$ atoms are out of the $\mathrm{COO}$ plane, thus allowing for $\mathrm{CH} \sigma^{*} / \pi^{*}$ coupling. By subtracting the MCA current from that of CAA over the range 0.1-1.3 eV in Figure 7, we can approximate the contribution to the $[\mathrm{M}-\mathrm{H}]^{-}$signal arising from the $\mathrm{OH}$ group of CAA, and this result is shown in Figure 8. The sharp peak at $0.68 \mathrm{eV}$ is accompanied by a broad and weak peak centered approximately at $0.9 \mathrm{eV}$.

Such features resemble closely the sharp structures in DEA spectra previously observed $44-47$ in the $[\mathrm{M}-\mathrm{H}]^{-}$current from the DNA/ RNA bases uracil, thymine, and cytosine. The latter have been assigned 47,48 to vibrational Feshbach resonances (VFRs) 49 arising from coupling between the stable dipole bound anion state and the temporary anion state associated with the lowest $\sigma^{*} \mathrm{MO}$, which has strongly

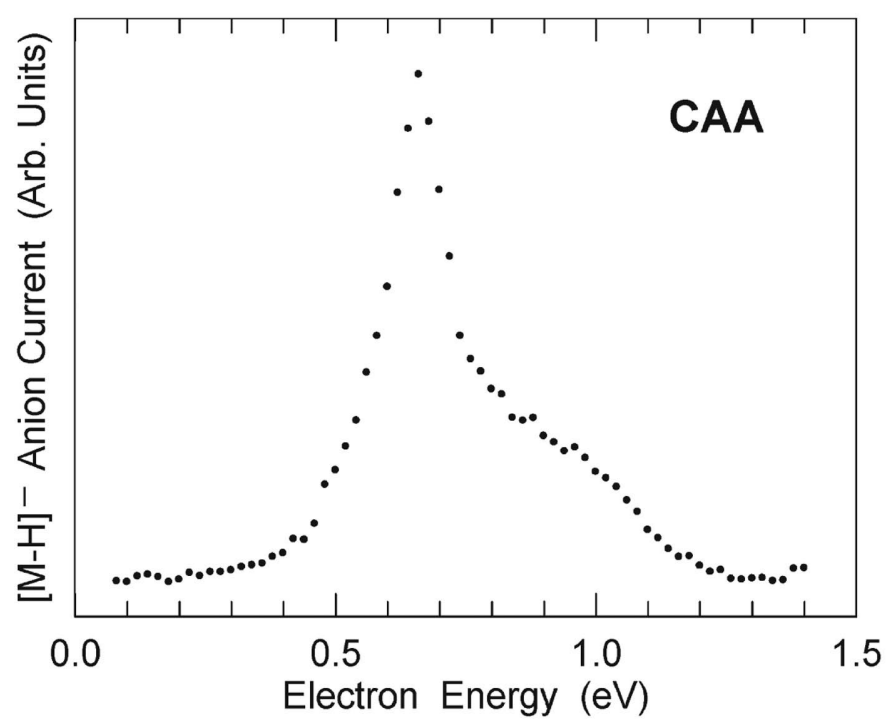

Figure 8. Contribution to $[\mathrm{M}-\mathrm{H}]^{-}$current from the $\mathrm{OH}$ group of CAA as a function of electron energy, obtained by subtraction of the component due to the $\mathrm{CH}_{2}$ group as it appears in MCA. 
antibonding $\mathrm{N}-\mathrm{H}$ character. The VFR peaks are found to lie at the energies of the $\mathrm{N}-\mathrm{H}$ stretching modes of the dipole bound anion state.

Because CAA has a much smaller dipole moment, calculated to be 2.48 D with the 6-31+G(d) basis set for the most stable conformer (1), CAA is more analogous to the $-\mathrm{COOH}$ bearing compounds $\mathrm{HCOOH}$ (formic acid), glycine, and other amino acids. Sharp structures in the yields of $[\mathrm{M}-\mathrm{H}]^{-}$from these compounds have also been observed. The results obtained by Abouaf ${ }^{\circ}$ display these structures with the highest energy resolution to date. The essential features have been replicated in calculations by Gallup et al. ${ }^{51}$ in formic acid and glycine. In these examples with subcritical dipole moments, the sharp features are closely tied to the locations of the $\mathrm{OH}$ stretching mode of the neutral molecule. If CAA is, in fact, supercritical then the peaks may be shifted slightly lower.

Consistent with the mechanisms discussed previously, the vibrational modes of the neutral that could give rise to VFR structures in the yield of $[\mathrm{M}-\mathrm{H}]^{-}$will be those that are excited by electron occupation of the empty $\sigma^{\star}(\mathrm{OH})$ orbital (LUMO +3 ) because of its strongly antibonding $\mathrm{OH}$ character. Thus, we expect structure near the energies of $v(\mathrm{OH})=1$ and 2, falling near 0.44 and $0.88 \mathrm{eV}$. The first of these falls below the estimated threshold energy for formation of $[\mathrm{M}-\mathrm{H}]^{-}$given earlier. The second is consistent with the energy of the weak feature shown in Figure 8 at $\sim 0.9 \mathrm{eV}$. Neither is consistent with the sharp peak at $0.68 \mathrm{eV}$.

Close examination of LUMO +3 shows that a portion of the wave function lies on the in-plane component of the $\mathrm{CN} \pi^{*}$ resonance. Thus, it is not unreasonable to expect that excitation of the $\mathrm{CN}$ stretching mode could also occur, with quanta of $0.28 \mathrm{eV}$. The combination mode $v(\mathrm{OH})=1+v(\mathrm{CN})=1$ lies at $0.72 \mathrm{eV}$, which, within the energy calibration error, agrees with the peak at $0.68 \mathrm{eV}$. Such combination modes were observed previously in thymine and uracil ${ }^{48}$ although they were much smaller in amplitude than the dominant $\mathrm{N}-\mathrm{H}$ stretching mode. While it is puzzling that $v=2$ of the $\mathrm{OH}$ stretch is not strong, calculations by Gallup and Fabrikant ${ }^{2}$ have shown that the relative amplitudes of VFR structures are very sensitive to the crossing point of the neutral and $\sigma^{\star}$ anionic potential curves.

As a final comment on the observed $[\mathrm{M}-\mathrm{H}]^{-}$currents, their connection with gas-phase acidities can be noted. To the extent to which 
the threshold energy $\left(E_{\mathrm{th}}\right)$ can be measured, the GPA is given experimentally by the ionization energy of $\mathrm{H}$ plus $E_{\text {th }}$. In CAA, the threshold is estimated to lie at $0.5 \pm 0.1 \mathrm{eV}$, leading to a GPA of $324 \mathrm{kcal} / \mathrm{mol}$. Extrapolating the anion current of MCA in Figure 7 to threshold yields a value about $0.3 \mathrm{eV}$ higher than that of CAA and thus a GPA less acidic by $6.9 \mathrm{kcal} / \mathrm{mol}$. The B3LYP/6-31+G(d) calculations predict an energy threshold (only electronic contributions) of $344.5 \mathrm{kcal} / \mathrm{mol}$ for production of $\mathrm{HCOO}^{-}$and $\mathrm{H}^{+}$from $\mathrm{HCOOH}$, in close agreement with the measured 53 gas-phase acidity $(345.3 \pm 2.2 \mathrm{kcal} / \mathrm{mol})$. According to the same calculations, the gas-phase acidity of CAA and MCA are 330.0 and $342.9 \mathrm{kcal} / \mathrm{mol}$, respectively, and the former is only $8.9 \mathrm{kcal} / \mathrm{mol}$ less acidic than $\mathrm{HBr}$.

The sharp structure displayed at $0.34 \mathrm{eV}$ by the total anion current in CAA lies below the threshold for $[\mathrm{M}-\mathrm{H}]^{-}$production and is not observed in the other mass-selected partial anion currents. Although this peak lies about $100 \mathrm{meV}$ below the $\mathrm{OH} v=1$ vibrational level, we tentatively propose that it could be a VFR associated with this mode. If this energy is below any possible fragmentation process, its presence in the total anion current but absence in the mass resolved data at the parent anion mass suggests that it could have a lifetime long enough to be detected at the walls of the collision chamber, but not sufficiently long (about $30 \mu \mathrm{s}$ ) for detection though the mass filter. A portion of the disparity in its energy may arise from the \pm 0.05 calibration error. More rapid autodetachment of the higher energy side of the feature may also contribute to an apparent shift to lower energy. We note that further support for association with the $v(\mathrm{OH})=$ 1 level is also given by the absence of this feature in the total current collected in MCA, which lacks the $\mathrm{OH}$ group.

\section{Conclusions}

The empty-level electronic structures of cyanoacetic acid (CAA) and its derivative methyl cyanoacetate (MCA) were investigated by means of electron transmission and dissociative electron attachment (DEA) spectroscopies, with the support of B3LYP and HF calculations, in connection with the possible use of CAA as an electron-acceptor anchored to $\mathrm{TiO}_{2}$ in dye-sensitized solar cells. In these dyes CAA is connected to 
the donor block by replacement of its $\mathrm{CH}_{2}$ group with an ethene group, so that the electron-acceptor molecule can be considered to be cyanoacrylic acid, a conjugated $\pi$-system for which the calculations predict a largely positive electron affinity.

Measurements of the total anion current at the walls of the collision chamber and mass-selected fragment negative currents, as a function of the incident electron energy, show that in the $\mathrm{o}-4 \mathrm{eV}$ energy range the total anion current is essentially accounted for only by the $[\mathrm{M}-\mathrm{H}]^{-}$(loss of a hydrogen atom from the molecular anion) and, with a sizably smaller intensity, the $\mathrm{CN}^{-}$species. Given that in the dye the hydrogen atoms of the $\mathrm{CH}_{2}$ group (replaced with an ethene double bond) are not present and the carboxyl group is anchored to $\mathrm{TiO}_{2}$, the DEA spectra indicate that the acceptor derived from CAA has a small (if any in the condensed phase) tendency to dissociation under conditions of excess negative charge. In fact, interactions with neighboring molecules in the condensed phase are likely to stabilize the molecular anion and prevent dissociation, as recently found in trinitrotoluene embedded into helium droplets. 44 Therefore, not only were the organic dyes with CAA as an acceptor found to give much higher efficiencies compared to those with rhodanine, ${ }^{11}$ but the present DEA data indicate that they should also achieve the important requirement of long-term stability.

In addition, this study showed that the total anion current of CAA displays unusually sharp features located at 0.34 and $0.68 \pm 0.05 \mathrm{eV}$ (whose widths are limited by the electron beam resolution), and the latter signal is prominent in the mass-selected $[\mathrm{M}-\mathrm{H}]^{-}$fragment anion current. These features resemble closely those previously observed in DNA bases, and are assigned to vibrational Feshbach resonances arising from coupling between an anion state associated with a dipole moment close to the critical value and a temporary $\sigma^{*}$ anion state. The intense sharp structure at $0.68 \mathrm{eV}$ in the $[\mathrm{M}-\mathrm{H}]^{-}$negative current is ascribed to combined excitations of the mainly $v(\mathrm{OH})$ and $v(\mathrm{CN})$ stretching vibrational modes.

Acknowledgments A.M. thanks the Italian Ministero dell'Istruzione, dell' Università e della Ricerca for financial support. The authors thank one of the reviewers for pointing out the connection between gas phase acidities and the production of $[\mathrm{M}-\mathrm{H}]^{-}$. 


\section{References}

(1) Aberle, A. G. Thin Solid Films 2009, 517, 4706.

(2) Krebs, F. C. Sol. Energy Mater. Sol. Cells 2009, 93, 394.

(3) Grätzel, M. Nature 2001, 414, 338.

(4) Nanotechnology for Next Generation Solar Cells. J. Phys. Chem. C [Online] vi, Virtual Issue 1, August 2009, http://pubs.acs.org/page/jpccck/vi/1

(5) Robertson, N. Angew. Chem., Int. Ed. 2006, 45, 2338.

(6) Hamann, T. W.; Jensen, R. A.; Martinson, A. B. F.; Van Ryswyk, H.; Hupp, J. T. Energy Environ. Sci. 2008, 1, 66.

(7) Segura, J. L.; Martín, N.; Guldi, D. M. Chem. Soc. Rev. 2005, 34, 31.

(8) Roquet, S.; Cravino, A.; Leriche, P.; Aléveque, O.; Frère, P.; Roncali, J. J. Am. Chem. Soc. 2006, 128, 3459.

(9) Liang, M.; Xu, W.; Cai, F.; Chen, P.; Peng, B.; Chen, J.; Li, Z. J. Phys. Chem. C 2007, 111, 4465.

(10) Xu, W; Peng, B.; Chen, J.; Liang, M.; Cai, F. J. Phys. Chem. C 2008, 112, 874.

(11) Park, S. S.; Won, Y. S.; Choi, Y. C.; Kim, J. H. Energy Fuels 2009, 23, 3732.

(12) Modelli, A.; Jones, D.; Pshenichnyuk, S. A. J. Phys. Chem. C 2010, 114, 1725.

(13) Pshenichnyuk, S. A.; Modelli, A. Internat. J. Mass Spectrom. 2010, 294, 93.

(14) Sanche, L.; Schulz, G. J. Phys. Rev. A: At., Mol., Opt. Phys. 1972, 5, 1672.

(15) Schulz, G. J. Rev. Mod. Phys. 1973, 45 (378), 423.

(16) Illenberger, E.; Momigny, J. Gaseous Molecular Ions. An Introduction to Elementary Processes Induced by Ionization; Steinkopff Verlag Darmstadt, Springer-Verlag: New York, 1992.

(17) Balog, R.; Langer, J.; Gohlke, S.; Stano, M.; Abdoul-Carime, H.; Illenberger, E. Internat. J. Mass Spectrom. 2004, 233, 267.

(18) Pelc, A.; Sailer, W.; Scheier, P.; Mason, N. J.; Illenberger, E.; Märk, T. D. Vacuum 2003, 70, 429.

(19) Scheer, A. M.; Mozejko, P.; Gallup, G. A.; Burrow, P. D. J. Chem. Phys. 2007, 126, 174301.

(20) Ibănescu, B. C.; May, O.; Monney, A.; Allan, M. Phys. Chem. Chem. Phys. 2007, 9, 3163.

(21) Becke, A. D. J. Chem. Phys. 1993, 98, 5648.

(22) Lee, C.; Yang, W.; Parr, R. G. Phys. Rev. B 1988, 37, 785.

(23) Modelli, A.; Jones, D.; Distefano, G. Chem. Phys. Lett. 1982, 86, 434.

(24) Johnston, A. R.; Burrow, P. D. J. Electron Spectrosc. Relat. Phenom. 1982, 25 , 119.

(25) Modelli, A.; Foffani, A.; Scagnolari, F.; Jones, D. Chem. Phys. Lett. 1989, 163, 269.

(26) Frisch, M. J.; Trucks, G. W.; Schlegel, H. B.; Scuseria, G. E.; Robb, M. A.; Cheeseman, J. R.; Montgomery, J. A.; Vreven, T.; Kudin, K. N.; Burant, J. C.; Millam, J. M.; Iyengar, S. S.; Tomasi, J.; Barone, V.; Mennucci, B.; Cossi, M.; 
Scalmani, G.; Rega, N.; Petersson, G. A.; Nakatsuji, H.; Hada, M.; Ehara, M.; Toyota, K.; Fukuda, R.; Hasegawa, J.; Ishida, M.; Nakajima, T.; Honda, Y.; Kitao, O.; Nakai, H.; Klene, M.; Li, X.; Knox, J. E.; Hratchian, H. P.; Cross, J. B.; Bakken, V.; Adamo, C.; Jaramillo, J.; Gomperts, R.; Stratmann, R. E.; Yazyev, O.; Austin, A. J.; Cammi, R.; Pomelli, C.; Ochterski, J. W.; Ayala, P. Y.; Morokuma, K.; Voth, G. A.; Salvador, P.; Dannenberg, J. J.; Zakrzewski, V. G.; Dapprich, S.; Daniels, A. D.; Strain, M. C.; Farkas, O.; Malick, D. K.; Rabuck, A. D.; Raghavachari, K.; Foresman, J. B.; Ortiz, J. V.; Cui, Q.; Baboul, A. G.; Clifford, S.; Cioslowski, J.; Stefanov, B. B.; Liu, G.; Liashenko, A.; Piskorz, P.; Komaroni, I.; Martin, R. L.; Fox, D. J.; Keith, T.; Al-Laham, M. A.; Peng, C. Y.; Nanayakkara, A.; Challacombe, M.; Gill, P. M. W.; Johnson, B.; Chen, W.; Wong, M. W.; Gonzalez, C.; Pople, J. A. Gaussian 03, revision D.o1; Gaussian Inc.: Wallingford, CT, 2004.

(27) Modelli, A.; Distefano, G.; Jones, D. Chem. Phys. 1982, 73, 395.

(28) Aflatooni, K.; Hitt, B.; Gallup, G. A.; Burrow, P. D. J. Chem. Phys. 2001, 115, 6489.

(29) Ng, L.; Balaji, V.; Jordan, K. D. Chem. Phys. Lett. 1983, 101, 171.

(30) Hitchcock, A. P.; Tronc, M.; Modelli, A. J. Phys. Chem. 1989, 93, 3068.

(31) Staley, S. S.; Strnad, J. T. J. Phys. Chem. 1994, 98, 161.

(32) Guerra, M. Chem. Phys. Lett. 1990, 167, 315.

(33) Chen, D. A.; Gallup, G. A. J. Chem. Phys. 1990, 93, 8893.

(34) Simons, J.; Jordan, K. D. Chem. Rev. 1987, 87, 535.

(35) Lane, N. F. Rev. Mod. Phys. 1980, 52, 29.

(36) Modelli, A. Phys. Chem. Chem. Phys. 2003, 5, 2923.

(37) Aflatooni, K.; Gallup, G. A.; Burrow, P. D. J. Chem. Phys. 200o, 104, 7359.

(38) Hehre, W. J.; Radom, L.; Schleyer, P. v. R.; Pople, J. A. Ab Initio Molecular Orbital Theory; Wiley: New York, 1986.

(39) Dunning, T. H., Jr.; Peterson, K. A.; Woon, D. E. Basis Sets: Correlation Consistent Sets in the Encyclopedia of Computational Chemistry; Schleyer, P. v. R., Ed.; John Wiley: Chichester, U.K., 1998.

(40) Modelli, A.; Hajgató, B.; Nixon, F. J.; Nyulászi, L. J. Phys. Chem. A 2004, 108, 7440.

(41) Stratmann, R. E.; Scuseria, G. E.; Frisch, M. J. J. Chem. Phys. 1998, 109, 8218.

(42) Modelli, A. J. Phys. Chem. A 2005, 109, 6193.

(43) Burrow, P. D.; Modelli, A.; Chiu, N. S.; Jordan, K. D. Chem. Phys. Lett. 1981, $80,270$.

(44) Mauracher, A.; Schöbel, H.; Ferreira da Silva, F.; Edtbauer, A.; Mitterdorfer, C.; Denifl, S.; Märk, T. D.; Illenberger, E.; Scheier, P. Phys. Chem. Chem. Phys. 2009, 11, 8240.

(45) Hanel, G.; Gstir, B.; Denifl, S.; Scheier, P.; Probst, M.; Farizon, B.; Farizon, M.; Illenberger, E.; Märk, T. D. Phys. Rev. Lett. 2003, 90, 188104.

(46) Denifl, S.; Ptasinska, S.; Cingel, M.; Matejcik, S.; Scheier, P.; Märk, T. D. Chem. Phys. Lett. 2003, 77, 74 . 
(47) Scheer, A. M.; Aflatooni, K.; Gallup, G. A.; Burrow, P. D. Phys. Rev. Lett. 2004, 92, 068102.

(48) Burrow, P. D.; Gallup, G. A.; Scheer, A. M.; Denifl, S.; Ptasinska, S.; Märk, T. D. D.; Scheier, P. J. Chem. Phys. 2006, 124, 124310.

(49) Hotop, H.; Ruf, M.-W.; Allan, M.; Fabrikant, I. I. Adv. At., Mol., Opt. Phys. 2003, 49, 85 .

(50) Abouaf, R. Chem. Phys. Lett. 2008, 451, 25.

(51) Gallup, G. A.; Burrow, P. D.; Fabrikant, I. I. Phys. Rev. A 2009, 79, 042701. (52) Gallup, G. A.; Fabrikant, I. I. Phys. Rev. A 2011, submitted for publication. (53) Kurinovich, M. A.; Lee, J. K. J. Am. Chem. Soc. 2000, 122, 6258. 